\title{
Minimally invasive aortic valve surgery
}

\author{
Lorenzo Di Bacco, Antonio Miceli, Mattia Glauber
}

U.O. Cardiochirurgia Mininvasiva, Istituto Clinico Sant'Ambrogio, Gruppo San Donato, Milano, Italy

Contributions: (I) Conception and design: All authors; (II) Administrative support: All authors; (III) Provision of study material or patients: None; (IV) Collection and assembly of data: L Di Bacco; (V) Data analysis and interpretation: L Di Bacco; (VI) Manuscript writing: All authors; (VII) Final approval of manuscript: All authors.

Correspondence to: Mattia Glauber. Istituto Clinico Sant'Ambrogio, Via Faravelli 16, 20149, Milano, Italy. Email: mattia.glauber@gmail.com.

\begin{abstract}
Since their introduction, it has been demonstrated that minimally invasive aortic valve replacement (MIAVR) approaches are safe and effective for the treatment of aortic valve diseases. To date, the main advantage of these approaches is represented by the reduced surgical trauma, with a subsequent reduced complication rate and faster recovery. This makes such approaches an appealing choice also for frail patients [obese, aged, chronic obstructive pulmonary disease (COPD)]. The standardization of the minimally invasive techniques, together with the implementation of preoperative workup and anesthesiological intraand post-operative care, led to an amelioration of surgical results and reduction of surgical times. Moreover, the improvement of surgical technology and the introduction of new devices such as sutureless and rapid deployment (SURD) valves, has helped the achievement of comparable results to traditional surgery. However, transcatheter technologies are nowadays more and more important in the treatment of aortic valve disease, also in low risk patients. For this reason surgeons should put new efforts for further reducing the surgical trauma in the future, even taking inspiration from other disciplines. In this review, we aim to present a review of literature evidences regarding minimally invasive treatment of aortic diseases, also reflecting our personal experience with MIAVR techniques. This review could represent a tool for a well-structured patient assessment and preoperative planning, in order to safely carrying out an MIAVR procedure with satisfactory outcomes.
\end{abstract}

Keywords: Minimally invasive; minimally invasive cardiac surgery aortic valve replacement (MICS AVR); aortic valve surgery; right anterior thoracotomy (RAT); ministernotomy (MS)

Submitted Apr 29, 2020. Accepted for publication Feb 08, 2021.

doi: $10.21037 /$ jtd-20-1968

View this article at: http://dx.doi.org/10.21037/jtd-20-1968

\section{Introduction}

In developed countries, thanks to the increase in life expectancy, degenerative aortic valve disorders are the most common cardiovascular diseases and their incidence increase with population's age (1). Nowadays full-sternotomy aortic valve replacement (AVR) is still considered the gold standard therapy (1), however, in the era of Transcatheter AVR, cardiac surgery has to catch up on the challenge of minimizing surgical trauma, promoting minimally invasive surgical accesses.

Since its introduction in the 90's minimally invasive cardiac surgery (MICS) has generated great interest (2), but during the following decades it hasn't reach the expected adoption, despite several studies have reported safety and reliability of these procedures (3).

In the last decade, the technological improvement in anesthesia, surgical techniques, myocardial protection strategies and postoperative practice allowed to treat also aged patients and at increased surgical risk, with excellent morbidity and mortality rates. To date many centers are adopting minimally invasive strategies to achieve AVR as an alternative to full sternotomy, maintaining or improving quality and results of conventional approaches. However, more efforts should be put in supporting a wider spread of these strategies. In this paper, we explore preoperative 
patient work-up and technical details of minimally invasive procedures and future perspectives in minimally invasive aortic valve replacement (MIAVR).

\section{Rational and definition}

The rational of minimally invasive aortic surgery is not only the performance of a small skin incision with good cosmetic results, but also to reduce the surgical trauma, lowering complications rate and blood loss, as well as shortening recovery time, even in fragile and older patients.

The Society of Thoracic Surgeons (STS) defines MICS as "any procedure not performed with a full sternotomy and cardiopulmonary (CPB) support" $(4,5)$. However, in 2008 the American Heart Association (AHA) defined in a scientific statement MICS as "a small chest wall incision that does not include the conventional full sternotomy". We do believe that AHA definition better describe the "concept and philosophy" of "minimally invasive cardiac surgery" which goal is to reduce the degree of surgical invasiveness without being procedure-specific (6).

Nowadays ministernotomy (MS) and right anterior thoracotomy (RAT) are the preferred approaches for MIAVR. Other minimally invasive surgical approaches are transverse sternotomy and right parasternal access from the second to the fourth costal cartilages.

\section{Preoperative work-up and technical consideration}

Minimally invasive approach needs a precise preoperative work-up because the key factor during the planning of these operations still remains safety and excellent outcome when compared to a traditional AVR (7).

A careful preoperative patient's assessment is mandatory, because some pre-existing conditions such as chest deformities, severe aortic calcifications, peripheral- and cerebrovascular disease, obstructive lung disease, previous cardiac or thoracic surgery and chest wall irradiation must be taken into account when planning MIAVR. These conditions may represent technical criticism in MICS.

In addition to routine preoperative tests, basal chest CT scan is particularly useful in planning MIAVR, as through this exam we can collect more information about chest wall, lung and airways anatomy as well as mediastinum and great vessel position (8). The presence of diaphragm supra-elevation, extreme pectus excavatum [Haller index $>3.2$, that is the ratio from maximal transverse diameter and narrowest anteroposterior diameter (9)] or carenatum and pleural adhesions may suggest an alternative approach, in particular if RAT was planned. In patients with previous cardiac surgery or chest irradiation, a thorax CT-scan allows to determine the distance between the posterior sternal table and the right ventricle. In case of previous coronary surgery [coronary artery bypass surgery (CABG)] the use of contrast media is recommended to study the position of patent left internal mammary artery and to asses if the graft crosses the midline, as in this case partial sternotomy could be technically demanding.

For the MS approach, CT scan is useful to decide the extension of sternal incision. In case of RAT the CT scan gives important information regarding the aorta and its relationship with the sternum; moreover CT helps to identify the closest intercostal space to the tip of the right atrial appendage, which is the preferred space for the right anterior minithoracotomy approach (8). RAT is more favorable if:

* More than one-half of ascending aorta is on the right-side of right parasternal line in the axial CT view (Figure 1A);

* The distance from the skin to the ascending aorta in correspondence of pulmonary artery bifurcation is inferior to $10 \mathrm{~cm}$;

* The angle between the midline and ascending aorta axis is $>45^{\circ}$ (Figure $1 B$ ).

Another issue in MICS is the arterial cannulation site. Direct ascending aorta cannulation is possible both in RAT and MS, assuring anterograde blood flow, which is better for brain perfusion; however, chest CT may give information about the presence of important anterior aortic wall calcifications that may discourage direct aortic cannulation. Aortic cannulation should also be avoided in case of aortic ectasia, especially in presence of bicuspid valve and bicuspid aortopathy that may determine problems of cannulation site management in minimally invasive set-up.

Peripheral arteriovenous cannulation is a viable alternative strategy to set up cardiopulmonary bypass (CPB). However, some concerns arise about retrograde arterial blood flow, suggesting a potential risk of cerebral embolism $(10,11)$. Although the relationship between retrograde flow and strokes has not been clearly demonstrated, some precautions should be adopted to reduce this risk: Doppler sonography of femoral vessels helps in measuring vessels dimension in order to establish the smallest size of the cannula that assures a correct flow; on the other hand, the cannula must not be too small, because a pressure over 

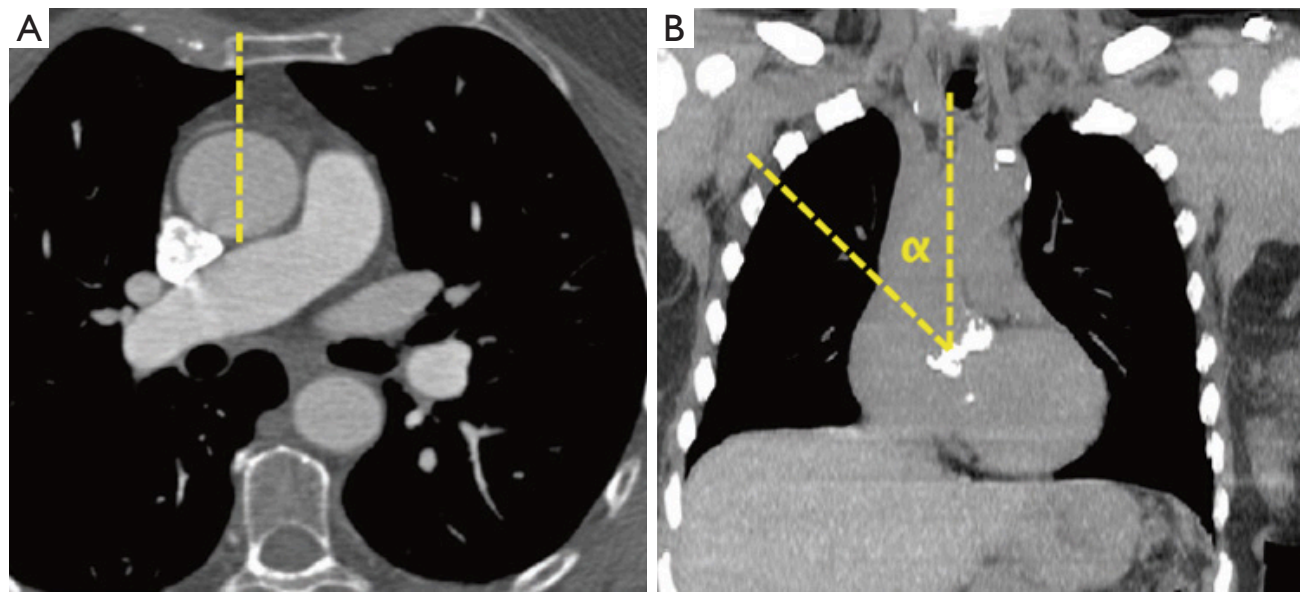

Figure 1 Chest CT-scan preoperative evaluation. (A) In the axial view of thorax CT-scans the ideal exposure of the ascending aorta is more than half of its circumference right sided respect to parasternal line (yellow scatted line), (B) in the coronal view of thorax CT-scans the ideal angle between midline (vertical yellow scatted line) and ascending aorta (obliquus yellow scatted line) is $45^{\circ}(\alpha$ angle).

$300 \mathrm{mmHg}$ may produce hemolysis or dissection. Moreover, the sonography can show the presence of vascular calcifications or stenosis, which could lead to retrograde dissection or calcium retrograde embolism. Right axillary artery is a viable alternative if both femoral arteries and ascending aorta are not suitable for cannulation due to heavy calcifications, but it is not routinely used in MIAVR (Table 1).

\section{Anesthesiological consideration}

MIAVR requires cooperation between all the staff that will take care of the patients, both physicians and nurses to reach the best result.

Anesthesiological support in MIAVR is essential to carry out the procedure with the lowest risk for the patient and to assure fast-track intensive care unit management. Moreover, to facilitate a rapid extubation, short-acting drug-based anesthesia should be considered. External defibrillator pads are required in MIAVR procedures, due to the limited working space for internal defibrillation. In addition to central venous catheter, a venous introducer should be placed in the right jugular vein to allow the placement of a temporary endovascular pacemaker catheter, in case epicardial wires can't be placed during surgery.

Intraoperative transesophageal echocardiography (TEE) is routinely used during femoral vessel cannulation with Seldinger technique. A TEE bi-caval view is showed during femoral vein cannulation to monitor the route of the guidewire in the superior vena cava, allowing correct positioning of the cannula and avoiding right atrium injuries or cannula malpositioning through the tricuspid valve. Moreover, during femoral artery cannulation, TEE should show the correct wire position in the thoracic aorta, avoiding the creation of a false lumen or retrograde dissection once CPB is started (8).

A pulmonary artery catheter can be placed, especially in high-risk patients to monitor the pulmonary pressure during and after surgery. For both MS and RAT, a doublelumen endotracheal tube or bronchial blocker could be employed, if they are tolerated by the patient, in order to allow selective pulmonary ventilation, improving exposure $(8,12)$. Nevertheless, in RAT setting the right lung can be displaced posteriorly by mechanical compression at low ventilation volumes without using selective lung ventilation $(8,12)$. However, right lung exclusion can be useful during surgeons learning curve and technically demanding operations.

In order to ameliorate venous drainage and prevent heart filling during $\mathrm{CPB}$, vacuum-assisted or kinetic venous drainage are commonly employed.

Intraoperative TEE is crucial for de-airing process in any MIAVR procedure. Once this maneuver is completed, the heart weaning from $\mathrm{CPB}$ will be allowed with minimal micro-embolization risk.

\section{Ministernotomy}

Ministernotomy is the most commonly adopted technique for MIAVR. A 6-8 cm vertical skin incision is performed on the midline. According to surgeon preference partial 


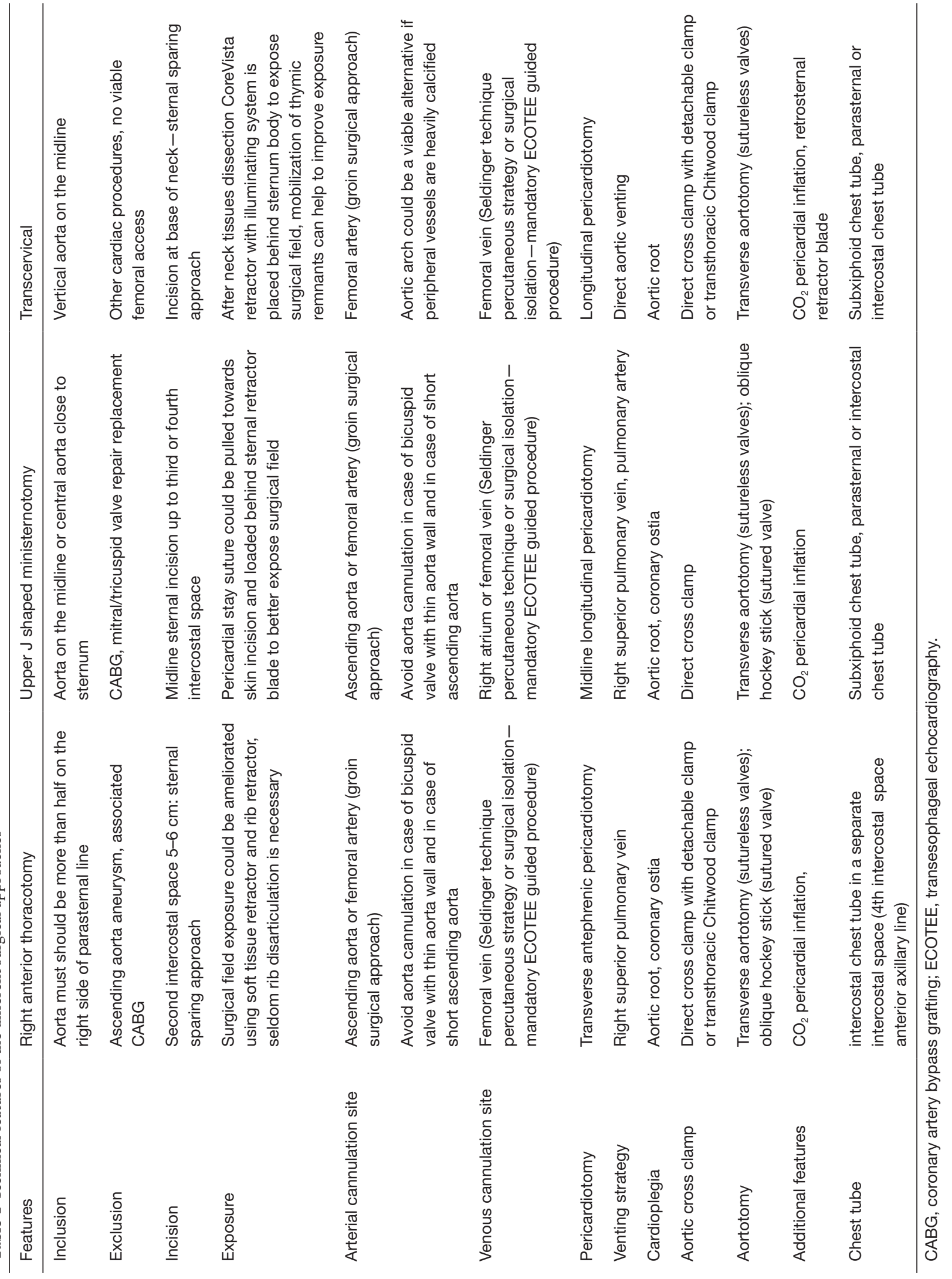


J-shaped sternotomy could be extended to the second, third or fourth intercostal space; an inverted $\mathrm{T}$ or V-shaped MS at the level of the second or third intercostal space can be chosen as an alternative $(4,13)$ (Figures 2,3).

A sternal saw is used to divide sternum from intercostal space to midline transversally and then the vertical part of partial sternotomy is performed. In MS approach, the right internal thoracic artery is routinely spared (8). In this operative setting, central aortic cannulation is usually adopted, but cannulation site should be aimed as distal as possible to provide a wide working space. Venous drainage can be achieved either through peripheral vein cannulation, surgical or percutaneous, or through a central cannulation with a cannula in the right atrium.

Cardioplegia could be delivered through aortic root or

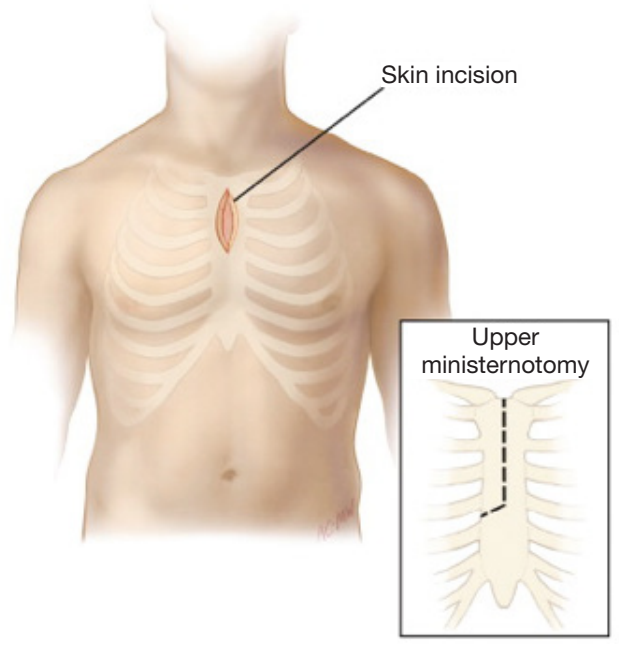

Figure 2 Upper right sided J-shaped ministernotomy.
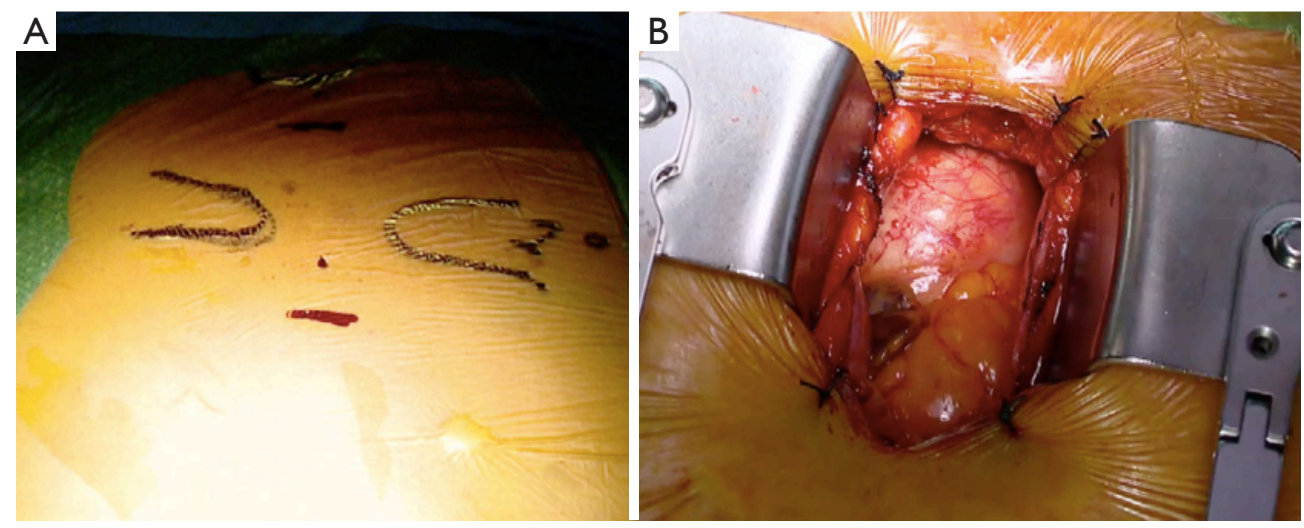

Figure 3 Exposure during aortic valve replacement in inverted V ministernotomy. (A) Skin drawing, (B) surgical exposure. directly through the coronary ostia if more than moderate aortic regurgitation is present or when additional doses are required (Figure 4).

If necessary, retrograde cardioplegia could be delivered either into coronary sinus or through a peripheral approach via internal jugular vein. Venting of the left ventricle can be achieved directly through the aortic valve or with a vent placed through the right superior pulmonary vein. Another viable strategy for left ventricle venting is to put a vent catheter in the pulmonary artery trunk. In order to obtain an easier closure of aortotomy at the end of surgery, this should be performed as high as possible, thus helping its visualization during hemostasis $(7,8)$.

Retraction sutures, if required, are placed on the edges of the aortotomy, and/or at the commissures to elevate the aortic valve into the center of the operative field improving valve exposure. Valve implantation is carried out similarly to a conventional approach and the procedure can be simplified using endoscopic instruments with long shafts or knotting devices, such as CoreKnot ${ }^{\circledR}$. This reduces valve implantation time, assuring a homogenous distribution of tension between the native annulus and the sewing ring, and avoids suture breaking, that can be challenging to replace in limited access space.

\section{Right anterior minithoracotomy}

Right anterior minithoracotomy approach allows AVR through a $4-6 \mathrm{~cm}$ skin incision at the second or third intercostal space, as close as possible to the parasternal line (Figure 5). Up on entering the pleural space, the right internal thoracic artery and veins are usually isolated, ligated with hemoclips and cut. Right internal thoracic artery could 
be spared in younger patients, but attention should be paid to avoid tension when soft tissue retractor or rib retractor is placed, due to the risk of intimal lesion or vessel abruption and bleeding.

According to surgeon preference, the third or fourth rib could be displaced from the sternum to obtain an unencumbered working space and visualize the tip of the right atrial appendage. A soft tissue retractor is inserted into the wound and if it is necessary a rib retractor with narrow blades can be used. Transverse pericardial opening is performed $2-3 \mathrm{~cm}$ anteriorly from the phrenic nerve to avoid nerve palsy and diaphragm paralysis. Pericardial opening should be performed on the aorta, in order to have the best exposure of surgical field, especially if a central cannulation is chosen. Exposure through a small surgical field can be difficult and it can be enhanced by placing pericardial stay sutures.

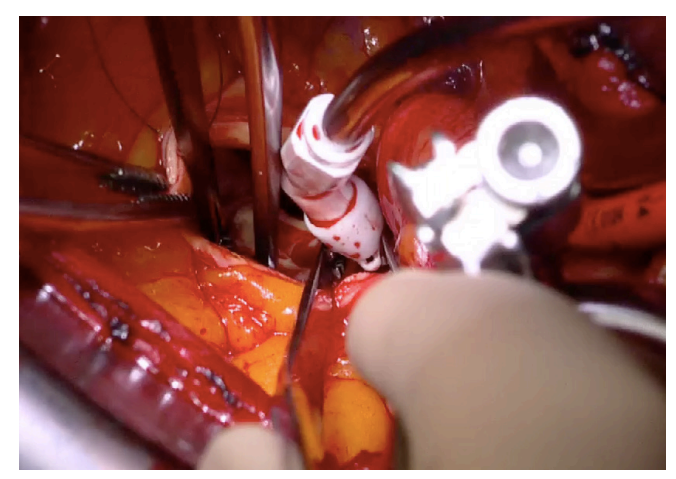

Figure 4 Cardioplegia delivery through the coronary ostia in ministernotomy.
Cannulation for $\mathrm{CPB}$ can be performed directly in the ascending aorta (Figure 6A,B), requiring advanced technical skills to place the purse-string in the distal ascending aorta and using a low profile arterial cannulas. Alternatively, peripheral cannulation is the preferred choice in case of difficult exposure and thin or short aorta. If central cannulation results in a limitation of surgical field exposure, peripheral cannulation for $\mathrm{CPB}$ should be chosen.

Venous cannulation can be performed either surgically or through a percutaneous puncture. The cross clamp can be applied through an alternative port if a Chitwood clamp is used (14). Alternatively, if a detachable clamp is used, aortic cross clamp could be performed directly from skin incision. Detachable clamps have different tip shapes, and in case of a short aorta, straight tips are preferred, allowing to clamp the proximal arch and have more space for the aortotomy (Figure 7).

Cardioplegia delivery can be administered through the root or directly into the coronary ostia. In MIAVR, and particularly in RAT setting, a bloodless surgical field is crucial. As a matter of fact, heart drainage can be enhanced by venting the left ventricle through the superior right pulmonary vein or with a catheter through the aortic valve.

Technical details of aortotomy, prosthetic valve implantation and aortotomy closure are similar to MS approach. A transverse aortotomy is preferred if a sutureless valve is chosen, while in case of conventional sutured prosthesis, a hockey stick aortotomy extended toward the non-coronary sinus should be performed in order to better expose the annulus. The aortic valve leaflets are cut off as usual; however, valve excision and decalcification must be carefully carried out, because the repair of an aortic annulus
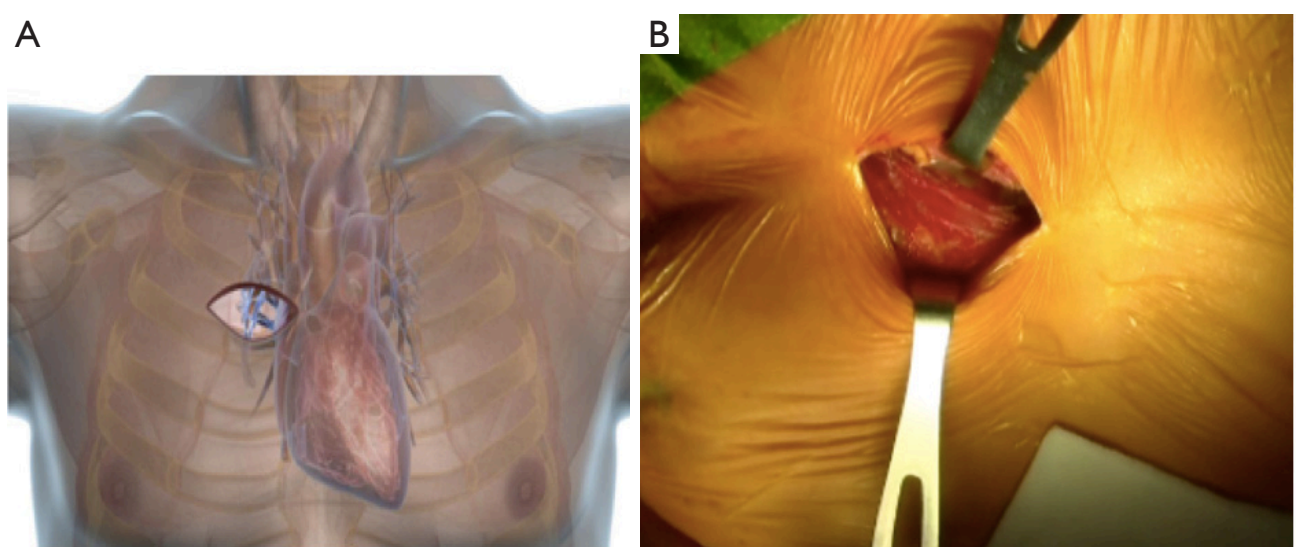

Figure 5 Right anterior minithoracotomy at second intercostal space. (A) RAT 3D animation rendering, (B) RAT surgical skin incision. RAT, right anterior thoracotomy. 

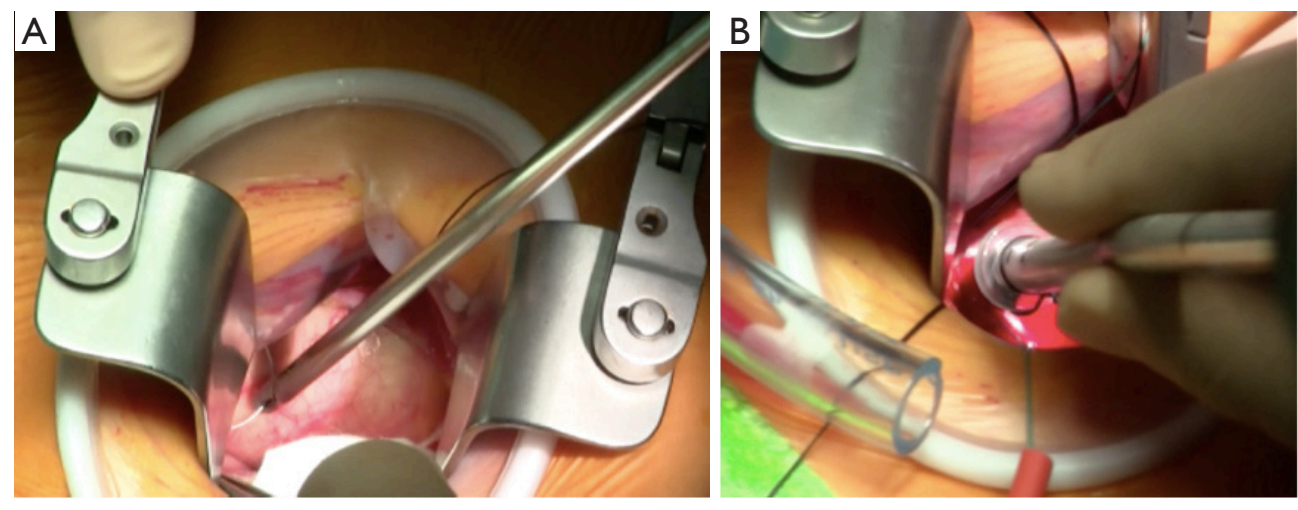

Figure 6 Direct aortic cannulation in right anterior minithoracotomy. (A) Purse-strings on ascending aorta for direct aorta cannulation in RAT. (B) Direct aorta cannulation in RAT. RAT, right anterior thoracotomy.

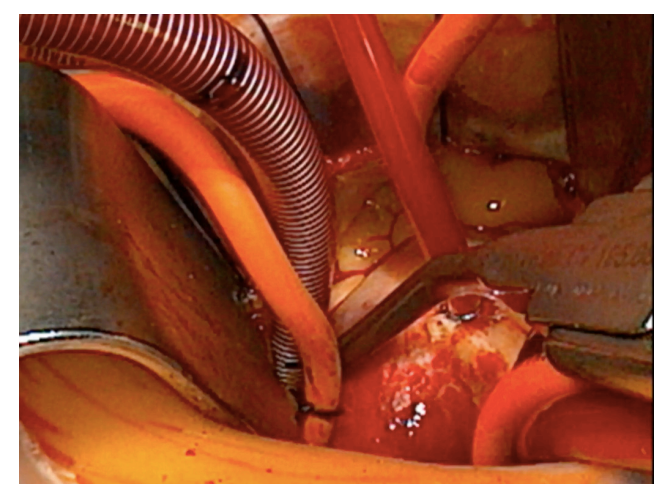

Figure 7 Aortic cross-clamp in RAT with detachable clamp. RAT, right anterior thoracotomy.

injury can be technically demanding in the RAT set-up.

Epicardial pacemaker wires should be placed before removing the aortic clamp. If a central cannulation strategy is chosen, the aortic cannula has to be removed before the venous one, with low arterial pressure; then the residual blood from the reservoir can be returned to the patient from the femoral venous line. If femoral vein has been cannulated with a percutaneous Seldinger strategy, the spindle can be reintroduced into the cannula during heparin reversal and removed once the patient is stable with groin compression.

At the end of the procedure, a chest drainage tube is inserted in the right pleural cavity through a separate intercostal space. Pericardium can be partially closed on the aorta or it can be left open. The disarticulated rib is reattached to the sternum using a non-absorbable, braided suture. To avoid lung herniation, the ribs are then reapproximated, using additional non-absorbable braided sutures (Table 1).

In 2009 we reported our first experience with MIAVR using RAT approach, showing excellent results in terms of mortality, morbidity, and patient recovery and quality of life (13). As above stated, if RAT AVR is planned, all patients should undergo thorax CT-scan to assess the anatomic relationship between the intercostal spaces, aorta and the aortic valve.

Major exclusion criteria for RAT approach are ascending aorta and/or root dilatation requiring surgery, while minor exclusion criteria are REDO surgery and previous right-sided pleuritic or major right chest trauma $(13,14)$. Moreover, in patients with severe lung emphysema this procedure should be avoided.

\section{A new challenge: transcervical AVR}

In the latest years a technique to achieve MIAVR through a transcervical access has been proposed. Cardiac surgery has taken inspiration from the transcervical thymectomy (TCT) described from Cooper in 1988, "borrowing" this technique from thoracic surgery to develop a new surgical approach (15).

TCT is performed through a transverse skin incision above sternal manubrium and once tissue dissection is completed a simple retractor is used to create the working space. Evidence that TCT can be performed with relatively low risk of non-serious adverse events has been demonstrated in several large series $(16,17)$.

Existing devices for TCT are unsuitable to perform AVR through this access. Therefore, an innovative surgical system has been introduced to address the lack of illumination inside mediastinal cavity and test MIAVR 

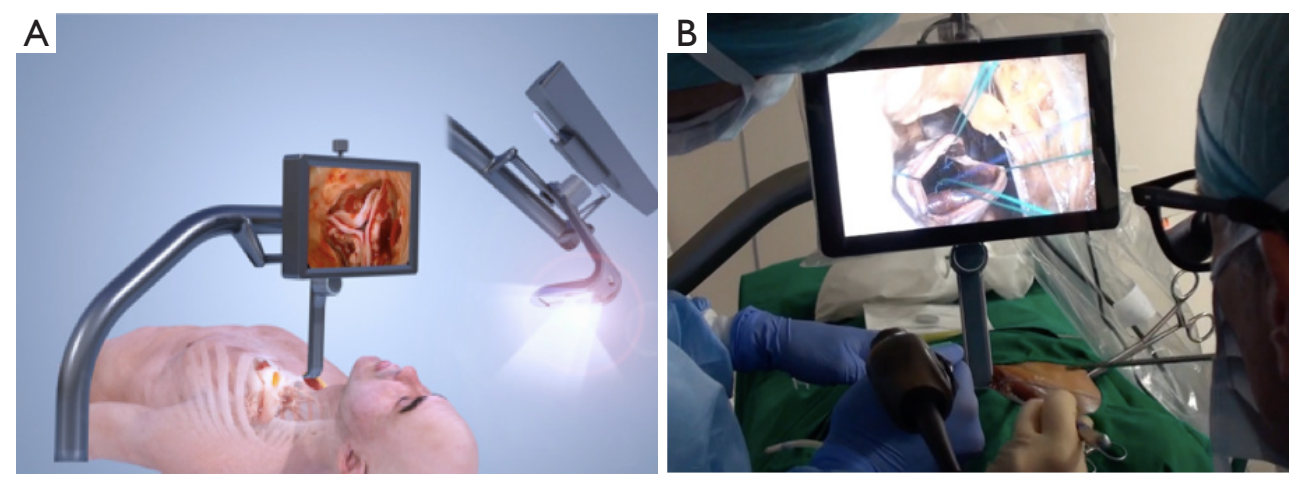

Figure 8 CoreVista; Cardio-Precision System. (A) CoreVista; Cardio-Precision System animation. (B) CoreVista aortic valve surgical view cadaver lab.

procedure (CoreVista; Cardio-Precision Ltd., Glasgow, $\mathrm{UK}$ ) (Figure $8 A, B$ ). The device is comprehensive of a robust lifting blade fixed to both table side; the retractor is equipped with a light set delivered through an optical switch, which is mounted on inferior surface of the retractor to give illumination to all the surgical field. A highresolution monitor covered with a transparent sterile towel is positioned above the retracting blade in the natural line of sight of the surgeon.

Also in this case, preoperative CT scan is essential in order to better assess spatial relationship between anatomical structures. Theoretically, this approach is feasible if measured distance from neck skin incision and aortic valve is between 12 and $15 \mathrm{~cm}$.

Surgery is performed through a skin crease incision in the neck. Initial dissection is directed under the sternum, anterior to the left brachiocephalic (innominate) vein, and a longitudinal pericardiotomy is performed to expose the ascending aorta.

CPB is established by femoro-femoral cannulation and usually a direct cross-clamp such as transthoracic (Chitwood) clamp is inserted percutaneously at the third intercostal space or directly through surgical incision. The clamping maneuver is performed under vision, and cardioplegia is delivered through the aortic root. The aorta is transversely opened and native valve excised. In this approach, a sutureless valve prostheses implant is necessary. After valve deployment, the aorta will be closed, the heart de-aired and the procedure completed (18).

This approach, designed to reduce surgical trauma and avoid pleural cavity entering directly in the mediastinum, requires advanced surgical skills in minimally invasive approaches. Only few cases have currently been performed with this approach and the results should be confirmed in larger trials. However, the encouraging feasibility study results allow suggesting that this surgical technique might represent a viable surgical strategy (Table 1).

\section{Comment}

Over the past two decades MIAVR has been gradually introduced into clinical practice. The increasing popularity of less invasive procedures allows surgeons to perform complex cardiac interventions with the same quality, even through small incisions.

Despite the improvement in surgical techniques, technologies and anesthesiological management, the debate about benefits of MICS is still open.

Several retrospective studies have tried to demonstrate whether minimally invasive aortic replacement can improve patients' outcomes, and reported data have showed safety and feasibility of minimally invasive approaches for AVR (3,19-22). Moreover, mortality rates are comparable between conventional and MICS, both in upper "J" shaped MS and in right minithoracotomy, when compared to mortality rates for isolate AVR in the STS Registry $(3,23)$.

Main findings of this studies are represented by lower rates of transfusions in patients undergoing MIAVR, as well as shorter ICU stay and hospital length of stay, if compared to conventional surgery, without prolonged surgical time, CPB and cross-clamp time (3,24-28). Furthermore, these studies report a reduced rate of pulmonary complications in patients treated with minimally invasive approaches (24-28).

Minimally invasive surgery for AVR is proven to be safe and to provide some advantages also in specific subset of patients such as elderly, obese and high risk patients. Lamelas 
et al. reported in 2012 that elderly patients undergoing AVR with Upper MS had shorter assisted ventilation time and faster recovery and hospital discharge (29), with a lower rate of prolonged hospitalization (29). Gilmanov et al. in 2013 reported same results in the same subset of patients undergoing AVR through RAT (30). Mortality remains lower and favorably compares to STS data, ranging from $0.0 \%$ to $1.7 \%$ (29-31).

Obesity is generally reported as a relative contraindication to MICS. However, data from Santana et al. and Welp and colleagues showed that minimally invasive approaches might have potential advantages on conventional surgery $(25,32)$. In this subset of patients MIAVR has a significantly lower rate of wound complications if compared to median sternotomy (31-32). Moreover, Welp and colleagues report a reduced rate of pulmonary complications between MS and sternotomy (ST) such as reintubation (MS: $0 \%$ vs. ST: $7.7 \%, \mathrm{P}=0.002$ ) and tracheostomy (MS: $0 \%$ vs. ST: $4.4 \%$, $\mathrm{P}=0.030$ ). Additionally, this study reports that also the need of blood products is reduced in MIAVR when compared to median sternotomy (25).

Although these experiences show several advantages of MIAVR in terms of low pulmonary complication rates, faster recovery time and shorter hospitalization duration, the surgical community still perceives that the major advantage of MICS is the cosmetic surgical results.

Several randomized controlled trials (RCTs) have assessed the efficacy and risks of MIAVR compared with conventional AVR (33-37). However, the small sample sizes and insufficient reporting of postoperative outcomes have left these studies underpowered. Furthermore, recently Phan and colleagues published a large meta-analysis involving 50 studies with 12.786 patients, pointing out that minimally invasive AVR is associated with low transfusion rates, intensive care and hospital length of stay, renal failure, with a mortality rate comparable to conventional AVR, even though the evidence quality was mostly very low (3).

One of the major criticisms that have limited the adoption of MIAVR techniques is the perception that these techniques are not "surgeon friendly", as they are more complex and technically demanding. However, in a previous experience we find out that, even though this procedure can be more complex if compared to a conventional approach, an expert tutor facilitates adaption to new instruments and surgical set-up, and reduces the rates of failure during the learning curve, with low risk for the patients (38).

Moreover, an adequate preoperative work-up may help in MIAVR planning and execution, in particular for RAT that, to be safely performed, requires attention in the study of relationship between aorta and chest wall, while MS is easier to plan.

To date it is not clear if the best minimally invasive approach for AVR is MS or RAT. Some retrospective studies have been published trying to answer this question. In our previous experience, we reported in 2014 a direct comparison of RT and MS for MIAVR. A non-randomized comparison of 406 consecutive patients with baseline characteristics was performed. Both approaches utilized central arterial and peripheral venous cannulation. We found that, although there was no difference in in-hospital mortality between the 2 approaches (RT $=1.2 \%, \mathrm{MS}=1.3 \%$; $\mathrm{P}=1$ ), RAT was associated with reduced postoperative morbidity in terms of reduced ventilation times, reduced ICU and hospital length of stay and reduced incidence of postoperative atrial fibrillation (AF) (39).

Fattouch et al. in 2016 compared outcomes of RAT and MS using conventional sutured valves: the study reports comparable outcomes in terms of mortality (MS: $3.3 \%$ vs. RAT: $1.1 \%, \mathrm{P}=0.28)$, stroke (MS: $0.4 \%$ vs. RAT: $0.0 \%$, $\mathrm{P}=0.32$ ) and need for transfusions (MS: $41.2 \% v s$. RAT: $40.6 \%, \mathrm{P}=0.87$ ). Higher bleeding though, requiring surgical revision, is reported (MS: 3.8\% vs. RAT: $8.0 \%, \mathrm{P}=0.006$ ), with similar ICU stay and hospital length of stay (40).

Similarly, Semsroth et al. reported in the Annals of Thoracic Surgery a retrospective propensity matched study comparing RAT and MS (41). In this study mortality was higher in the RAT group (3.8\%) than the MS (1.3\%), but it did not reach significant relevance. In the matched samples, no differences are reported for major outcomes (revision for bleeding, acute renal failure, wound infection and ICU duration). CPB duration and cross-clamp time were longer in RAT, respectively 137 vs. $113 \mathrm{~min}(\mathrm{P}<0.001)$ and 93 vs. $75 \min (\mathrm{P}<0.001)$. Furthermore, in the RAT group a surprisingly higher rate of conversion was reported (RAT $13.1 \%$ vs. MS $4.4 \%, \mathrm{P}=0.004)$. As a matter of facts, RAT procedure may therefore have been affected more by the learning curve. Conversion rate for RAT ranges from $1.0 \%$ to $3.8 \%(24,26,30,42)$ (Table 2).

Despite the technological improvement of the latest years, cardiac surgery is still losing the challenge with TAVI in the treatment of aortic valve stenosis, which application is increasingly used also in patients with low surgical risk $(43,44)$. The new challenge is to make surgery appealing again.

In the last decade, the introduction of SURD valves has given a new incentive to the research on MICS. As 


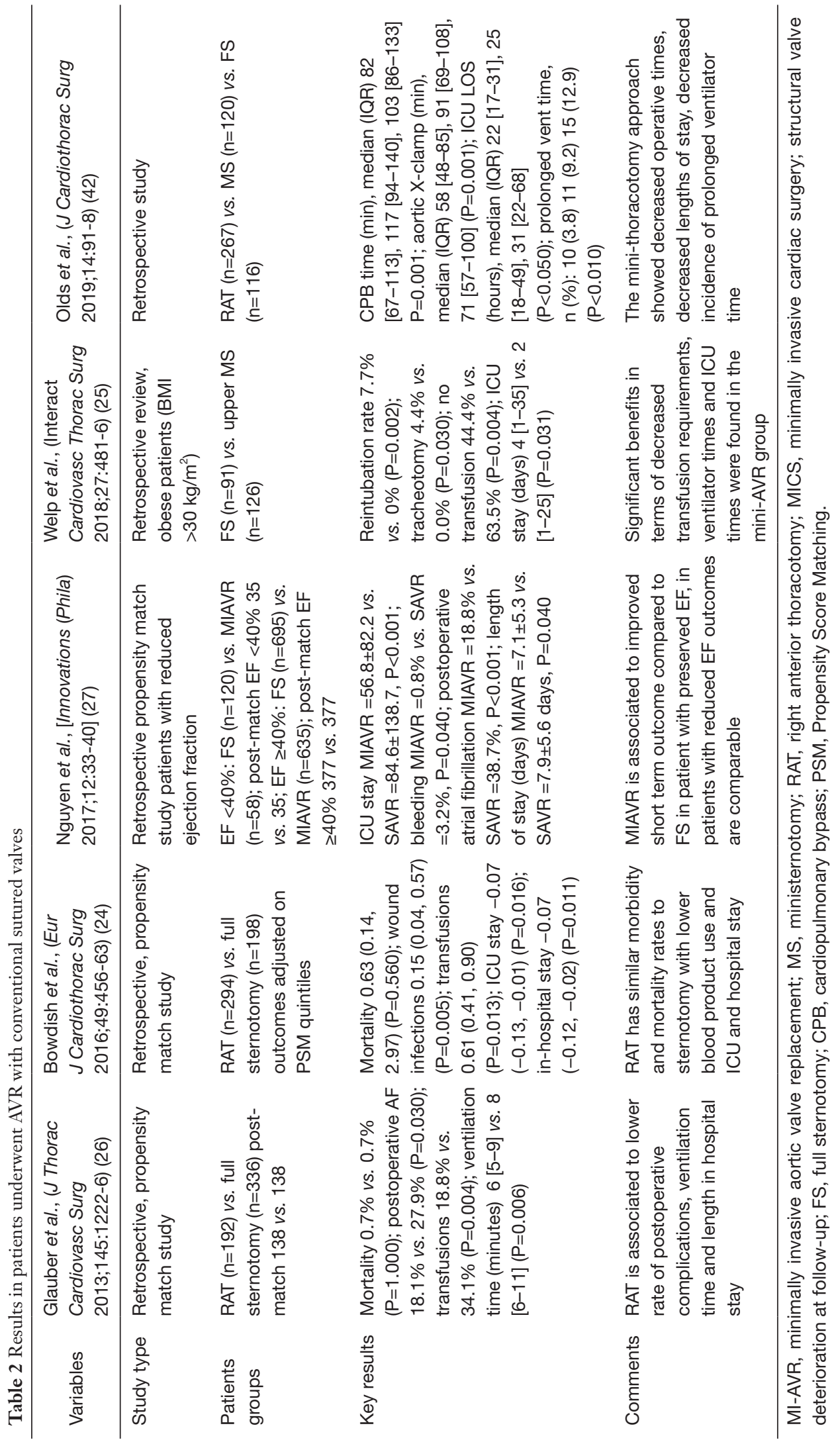


Table 3 Results of AVR with sutureless valves in MIAVR patients

\begin{tabular}{|c|c|c|c|c|c|}
\hline Variables & $\begin{array}{l}\text { Berretta } \\
\text { et al., (EJCTS } \\
\text { 2019;56:793-799) (50) }\end{array}$ & $\begin{array}{l}\text { Santarpino et al., } \\
\text { (Ann Thorac Surg } \\
\text { 2020;110:553-557) (51) }\end{array}$ & $\begin{array}{l}\text { Glauber et al., } \\
\text { (Innovations } \\
2020 ; 15: 120-130)(52)\end{array}$ & $\begin{array}{l}\text { Borger et al., } \\
\text { (Eur J Cardiothorac Surg } \\
2016 ; 50: 713-20) \text { (49) }\end{array}$ & $\begin{array}{l}\text { Pfeiffer et al., } \\
\text { (J Cardiovasc Surg } \\
2017 ; 58: 731-738)(48)\end{array}$ \\
\hline Comments & $\begin{array}{l}\text { Minimally invasive } \\
\text { SURD-AVR using } \\
\text { both Perceval } \\
\text { and Intuity valves } \\
\text { appeared a safe } \\
\text { and reproducible } \\
\text { procedure associated } \\
\text { with promising early } \\
\text { results }\end{array}$ & $\begin{array}{l}\text { Minimally invasive } \\
\text { reoperative AVR } \\
\text { with a sutureless or } \\
\text { rapid-deployment } \\
\text { prosthesis is a safe } \\
\text { and feasible, with fast } \\
\text { recovery and improved } \\
\text { postoperative outcome } \\
\text { with no mortality } \\
\text { and an acceptable } \\
\text { complication rate }\end{array}$ & $\begin{array}{l}\text { MI-AVR with Perceval } \\
\text { valve confirmed to be } \\
\text { safe, reproducible, } \\
\text { and effective in an } \\
\text { intermediate-risk } \\
\text { population, providing } \\
\text { excellent clinical } \\
\text { recovery both in early } \\
\text { and mid-term follow- } \\
\text { up }\end{array}$ & $\begin{array}{l}\text { MIS-RDAVR is associated } \\
\text { with a significantly } \\
\text { reduced cross-clamp } \\
\text { time and better valvular } \\
\text { haemodynamic function } \\
\text { than FS. However, PVL are } \\
\text { higher in MIAVR }\end{array}$ & $\begin{array}{l}\text { The minimally invasive } \\
\text { approach confers a } \\
\text { protective effect against } \\
\text { bleeding complications, } \\
\text { but it is time-consuming. } \\
\text { The use of sutureless } \\
\text { valve is associated with } \\
\text { significantly shorter } \\
\text { surgical times compared } \\
\text { with stented valves }\end{array}$ \\
\hline
\end{tabular}

MI-AVR, minimally invasive aortic valve replacement; MS, ministernotomy; RAT, right anterior thoracotomy; PPM, permanent pacemaker; MICS, minimally invasive cardiac surgery, structural valve deterioration at follow-up; FS, full sternotomy; CPB, cardiopulmonary bypass.

a matter of fact, these devices, that can be implanted without anchoring sutures, can significantly reduce $\mathrm{CPB}$ and ACC times (8), which are identified as determinant for postoperative complications (19). Safety and effectiveness of SURD valves has been demonstrated in several studies (45-49) (Table 3). Moreover, the possibility to implant these valves without placing anchoring sutures makes these devices the ideal choice in minimally invasive set up.

To date, few studies report the outcomes of SURD valve used in MICS. In the SURE registry, an international registry reporting the results of 480 MIAVR (MS and RAT) patients treated with sutureless valves (Figure 9) with a mean preoperative EuroSCORE I of 7.9\% (52), no conversions to median sternotomy are reported and mortality at 30 days was $0.4 \%$. A sutureless valve was implanted successfully in $98 \%$ of patients and at five years mean survival rate was $91.5 \%$ and freedom from valve related reoperation was $96.2 \%$.

In 2019, data from SURD registry on 1,935 patients treated with minimally invasive surgery and SURD valves were reported: conversion rate was $1 \%$ and failure implant rate was $1.4 \%(50)$. A low mortality rate of $1.7 \%$ was reported, that favorably compares to STS mortality rate for AVR.

Results of SURE and SURD registry in terms of CPB and ACC compare favorably with those reported in other 


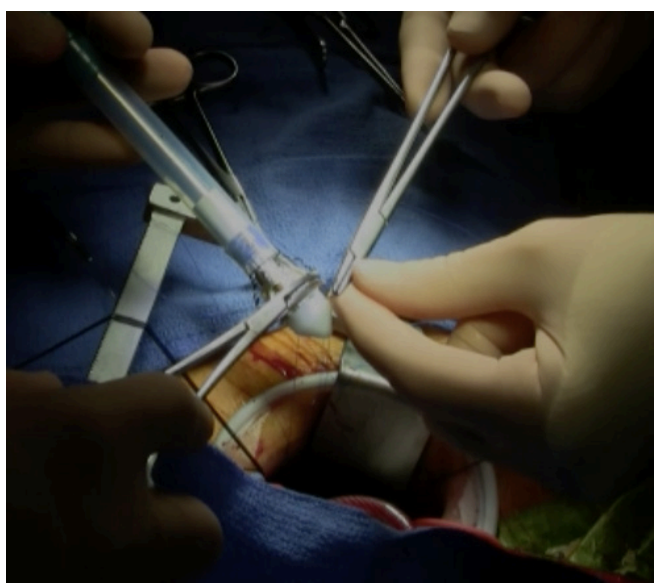

Figure 9 Sutureless Perceval S (LivaNova, UK) bioprosthesis implantation in right anterior minithoracotomy setting.

conventional AVR registries, such as the GARY (CPB time $84 \mathrm{~min}, \mathrm{XC}$ time $60 \mathrm{~min}$ ) and the STS database (CPB time 104.9 min, XC time $77 \mathrm{~min})(53,54)$.

Recently, Santarpino et al. have published on the use of SURD valves in minimally invasive set-up in REDO patients. Surgeries were carried out both by RAT and MS. No conversion was required as well as no mortality were reported in this study (51). Even if MIAVR was performed in REDO patients, CPB and ACC were not different from reported data from STS and GARY.

Some centers have already reported a totally endoscopic AVR replacement using SURD valves with only $0.8 \%$ of mortality (55).

\section{Conclusions}

Nowadays, minimally invasive aortic valve surgery is a safe and reproducible procedure. Technology improvements and adequate patient selection through a tailored preoperative work-out have reduced procedure related complications and therefore have made minimally invasive approaches as reliable as conventional surgery. Long CPB and in particular cross-clamp time, in patients undergoing AVR through RAT, remain the major drawback of this approach. The combination of MIAVR and SURD valves may represent the future of cardiac surgery, minimizing the surgical trauma and pump time, giving to patients the best possible treatment option with all the advantages of surgical AVR and short operative and recovery time. While this is important in low surgical risk patients, it could be important also for high risk "operable patients".

\section{Acknowledgments}

We thank CardioPrecision for letting us test their innovative single use CoreVista ${ }^{\circledR}$ Retractor and CoreVista ${ }^{\circledR}$ Accessories to perform trans-cervical AVR, as a first Italian experience.

Funding: None.

\section{Footnote}

Provenance and Peer Review: This article was commissioned by the Guest Editors (Jason Ali and Yasir Abu-Omar) for the series "Minimally Invasive Cardiac Surgery" published in Fournal of Thoracic Disease. The article has undergone external peer review.

Conflicts of Interest: All authors have completed the ICMJE uniform disclosure form (available at http://dx.doi. org/10.21037/jtd-20-1968). The series "Minimally Invasive Cardiac Surgery" was commissioned by the editorial office without any funding or sponsorship. AM serves as an unpaid editorial board member of Fournal of Thoracic Disease from Feb 2021 to Jan 2023. Dr. AM and Dr. MG report personal fees from LivaNova, outside the submitted work. The authors have no other conflicts of interest to declare.

Ethical Statement: The authors are accountable for all aspects of the work in ensuring that questions related to the accuracy or integrity of any part of the work are appropriately investigated and resolved.

Open Access Statement: This is an Open Access article distributed in accordance with the Creative Commons Attribution-NonCommercial-NoDerivs 4.0 International License (CC BY-NC-ND 4.0), which permits the noncommercial replication and distribution of the article with the strict proviso that no changes or edits are made and the original work is properly cited (including links to both the formal publication through the relevant DOI and the license). See: https://creativecommons.org/licenses/by-nc-nd/4.0/.

\section{References}

1. Carabello BA, Paulus WJ. Aortic stenosis. Lancet 2009;373:956-66.

2. Cosgrove DM III, Sabik JF. Minimally invasive approach for 
aortic valve operations. Ann Thorac Surg 1996;62:596-7.

3. Phan K, Xie A, Di Eusanio M, et al. A meta-analysis of minimally invasive versus conventional sternotomy for aortic valve replacement. Ann Thorac Surg 2014;98:1499-511.

4. Schmitto JD, Mokashi SA, Cohn LH. Minimally invasive valve surgery. J Am Coll Cardiol 2010;56:455-62.

5. STS National Database Spring 2003, Executive summary, Duke Clinical Research Institute, Durham, NC; 2003.

6. Indraratna P, Tian DH, Yan TD, et al. Transcatheter aortic valve implantation versus surgical aortic valve replacement: a meta-analysis of randomized controlled trials. Int J Cardiol 2016;224:382-7.

7. Mihaljevic T, Cohn LH, Unic D, et al. One thousand minimally invasive valve operations: early and late results. Ann Surg 2004;240:529-34.

8. Glauber M, Miceli A. Minimally Invasive Aortic Valve Surgery, Cardiac Surgery, A Complete Guide; 2019;46;421-8.

9. Klein P, Klop IDG, Kloppenburg GLT, et al. Planning for minimally invasive aortic valve replacement: key steps for patient assessment. Eur J Cardiothorac Surg 2018;53:ii3-ii8.

10. Murzi M, Cerillo AG, Miceli A, et al. Antegrade and retrograde arterial perfusion strategy in minimally invasive mitral-valve surgery: a propensity score analysis on 1280 patients. Eur J Cardiothorac Surg 2013;43:e167-72.

11. Mikus E, Turci S, Calvi S, et al. Aortic valve replacement through right minithoracotomy: is it really biologically minimally invasive? Ann Thorac Surg 2015;99:826-30.

12. Parnell A. Prince M. Anaesthesia for minimally invasive cardiac surgery. BJA Education 2018;18:323-30.

13. Glauber M, Karimov JH, Farneti PA, et al, Minimally invasive mitral valve surgery via right minithoracotomy. Multimed Man Cardiothorac Surg 2009;2009:mmcts.2008.003350.

14. Hinna Danesi T, Salvador L. Minimally invasive aortic valve replacement techniques using endoscopic surgery: 'must dos' and 'preferences'. Eur J Cardiothorac Surg 2018;53:ii27-ii28.

15. Cooper JD, Al-Jilaihawa AN, Pearson FG, et al. An improved technique to facilitate transcervical thymectomy for myasthenia gravis. Ann Thorac Surg 1988;45:242-7.

16. Shrager JB. Extended transcervical thymectomy: the ultimate minimally invasive approach. Ann Thorac Surg 2010;89:S2128-S2134.

17. de Perrot M, Bril V, McRae K, et al. Impact of minimally invasive trans-cervical thymectomy on outcome in patients with myasthenia gravis. Eur J Cardiothorac Surg 2003;24:677-83.

18. Dapunt OE, Luha O, Ebner A, et al. First-in-Man
Transcervical Surgical Aortic Valve Replacement Using the CoreVista System. Innovations 2016;11:84-93.

19. Murtuza B, Pepper JR, Satnbridge RD, et al. Minimal access aortic valve replacement: is it worth it? Ann Thorac Surg 2008;85:1121-31.

20. Scarci M, Young C, Fallouh H. Is ministernotomy superior to conventional approach for aortic valve replacement? Interact Cardiovasc Thorac Surg 2009;9:314-7.

21. Khoshbin E, Prayaga S, Kinsella J, et al. Ministernotomy for aortic valve replacement reduces the length of stay in the cardiac intensive care unit: meta-analysis of randomized controlled trials. BMJ Open 2011;1:e00266.

22. Brown ML, McKellar SH, Sundt TM, et al. Ministernotomy versus conventional sternotomy for aortic valve replacement: a systematic review and meta-analysis. J Thorac Cardiovasc Surg 2009;137:670-679.e5.

23. Brown JM, O’Brien SM, Wu C, et al. Isolated aortic valve replacement in North America comprising 108,687 patients in 10 years: changes in risks, valve types, and outcomes in the Society of Thoracic Surgeons National Database. J Thorac Cardiovasc Surg 2009;137:82-90.

24. Bowdish ME, Hui DS, Cleveland JD, et al. A comparison of aortic valve replacement via an anterior right minithoracotomy with standard sternotomy: a propensity score analysis of 492 patients. Eur J Cardiothorac Surg 2016;49:456-63.

25. Welp HA, Herlemann I, Martens S, et al. Outcomes of aortic valve replacement via partial upper sternotomy versus conventional aortic valve replacement in obese patients. Interact Cardiovasc Thorac Surg 2018;27:481-6.

26. Glauber M, Miceli A, Gilmanov D, et al. Right anterior minithoracotomy versus conventional aortic valve replacement: a propensity score matched study. J Thorac Cardiovasc Surg 2013;145:1222-6.

27. Nguyen TC, Thourani VH, Pham JQ, et al. Traditional Sternotomy Versus Minimally Invasive Aortic Valve Replacement in Patients Stratified by Ejection Fraction. Innovations (Phila) 2017;12:33-40.

28. Stoliński J, Plicner D, Grudzień G, et al. A comparison of minimally invasive and standard aortic valve replacement. J Thorac Cardiovasc Surg 2016;152:1030-9.

29. Lamelas J, Sarria A, Santana O, et al. Outcomes of minimally invasive valve surgery versus median sternotomy in patients age 75 years or greater. Ann Thorac Surg 2011;91:79-84.

30. Gilmanov D, Farneti PA, Ferrarini M, et al. Full sternotomy versus right anterior minithoracotomy for isolated aortic valve replacement in octogenarians: a 
propensity-matched study. Interact Cardiovasc Thorac Surg 2015;20:732-41; discussion 741.

31. Pisano C, Totaro P, Triolo OF, et al. Advantages of Minimal Access Versus Conventional Aortic Valve Replacement in Elderly or Severely Obese Patients. Innovations 2017;12:102-8.

32. Santana O, Reyna J, Grana R, et al. Outcomes of minimally invasive valve surgery versus standard sternotomy in obese patients undergoing isolated valve surgery. Ann Thorac Surg 2011;91:406-10.

33. Dogan S, Dzemali O, Wimmer-Greinecker G, et al. Minimally invasive versus conventional aortic valve replacement: a prospective randomized trial. J Heart Valve Dis $2003 ; 12: 76-80$.

34. Aris A, Camara ML, Montiel J, et al. Ministernotomy versus median sternotomy for aortic valve replacement: a prospective, randomized study. Ann Thorac Surg 1999;67:1583-7; discussion 1587-8.

35. Mächler HE, Bergmann P, Anelli-Monti M, et al. Minimally invasive versus conventional aortic valve operations: a prospective study in 120 patients. Ann Thorac Surg 1999;67:1001-5.

36. Bonacchi M, Prifti E, Giunti G, et al. Does ministernotomy improve postoperative outcome in aortic valve operation? A prospective randomized study. Ann Thorac Surg 2002;73:460-5.

37. Moustafa MA, Abdelsamad AA, Zakaria G, et al. Minimal vs median sternotomy for aortic valve replacement. Asian Cardiovasc Thorac Ann 2007; 15:472-5.

38. Murzi M, Cerillo AG, Bevilacqua S, et al. Traversing the learning curve in minimally invasive heart valve surgery: a cumulative analysis of an individual surgeon's experience with right minithoracotomy approach for aortic valve replacement. Eur J Cardiothorac Surg 2012;41:1242-6.

39. Miceli A, Murzi M, Gilmanov M, et al. Minimally invasive aortic valve replacement using right minithoracotomy is associated with better outcomes than ministernotomy. J Thorac Cardiovasc Surg 2014;148:133-7.

40. Fattouch K, Moscarelli M, Del Giglio M, et al. Nonsutureless minimally invasive aortic valve replacement: mini-sternotomy versus mini-thoracotomy: a series of 1130 patients. Interact Cardiovasc Thorac Surg 2016;23:253-8.

41. Semsroth S, Matteucci-Gothe R, Heinz A, et al. Comparison of Anterolateral Minithoracotomy Versus Partial Upper Hemisternotomy in Aortic Valve Replacement. Ann Thorac Surg 2015;100:868-73.

42. Olds A, Saadat S, Azzolini A, et al. Improved operative and recovery times with mini-thoracotomy aortic valve replacement. J Cardiothorac Surg 2019;14:91.

43. Mack MJ, Leon MB, Thourani VH, et al. Transcatheter Aortic-Valve Replacement with a Balloon-Expandable Valve in Low-Risk Patients. N Engl J Med 2019;380:1695-705.

44. Hirji SA, Funamoto M, Lee J, et al. Minimally invasive versus full sternotomy aortic valve replacement in lowrisk patients: Which will stand against transcatheter aortic valve replacement? Surgery 2018;164:282-7.

45. Folliguet TA, Laborde F, Zannis K, et al. Sutureless perceval aortic valve replacement: results o two European centers. Ann Thorac Surg 2012;93:1483-8.

46. Kocher AA, Laufer G, Haverich A, et al. One-year outcomes of the surgical treatment of aortic stenosis with a next generation surgical aortic valve (TRITON) trial: a prospective multicenter study of rapid-deployment aortic valve replacement with the EDWARDS INTUITY valve system. J Thorac Cardiovasc Surg 2013;145:110-5.

47. Martens S, Sadowski J, Eckstein FS, et al. Clinical experience with the ATS $3 \mathrm{f}$ Enable(R) Sutureless Bioprosthesis. Eur J Cardiothorac Surg 2011;40:749-55.

48. Pfeiffer S, Dell'aquila AM, Vogt F, et al. Efficacy of sutureless aortic valves in minimally invasive cardiac surgery: an evolution of the surgical technique. J Cardiovasc Surg (Torino) 2017;58:731-8.

49. Borger MA, Dohmen PM, Knosalla C, et al. Haemodynamic benefits of rapid deployment aortic valve replacement via a minimally invasive approach: 1 -year results of a prospective multicentre randomized controlled trial. Eur J Cardiothorac Surg 2016;50:713-20.

50. Berretta P, Andreas M, Carrel TP, et al. Minimally invasive aortic valve replacement with sutureless and rapid deployment valves: a report from an international registry (Sutureless and Rapid Deployment International Registry). Eur J Cardiothorac Surg 2019;56:793-9.

51. Santarpino G, Berretta P, Kappert U, et al. Minimally Invasive Redo Aortic Valve Replacement: Results From a Multicentric Registry (SURD-IR). Ann Thorac Surg 2020;110:553-7.

52. Glauber M, Di Bacco L, Cuenca J, et al. Minimally Invasive Aortic Valve Replacement with Sutureless Valves: Results From an International Prospective Registry. Innovations (Phila) 2020;15:120-30.

53. Thourani VH, Suri RM, Gunter RL, et al. Contemporary real-world outcomes of surgical aortic valve replacement in 141,905 low-risk, intermediate-risk, and high-risk patients. Ann Thorac Surg 2015;99:55-61.

54. Fujita B, Ensminger S, Bauer T, et al. Trends in practice and outcomes from 2011 to 2015 for surgical aortic valve 
replacement: an update from the German Aortic Valve Registry on 42776 patients. Eur J Cardiothorac Surg 2018;53:552-9.

Cite this article as: Di Bacco L, Miceli A, Glauber M. Minimally invasive aortic valve surgery. J Thorac Dis 2021;13(3):1945-1959. doi: 10.21037/jtd-20-1968
55. Cresce GD, Sella M, Hinna Danesi T, et al. Minimally Invasive Endoscopic Aortic Valve Replacement: Operative Results. Semin Thorac Cardiovasc Surg 2020;32:416-23. 